other hybrids in which hereditary characters from parental wild species are prominent, a noticeable absence of leaf spotting is again the rule.

In both the species and hybrid collections it is to be noted that infections described as mild are all characteristically of one kind, spotting occurring only on the oldest leaf. Recent field observation on plots of I.C.2, located in different parts of the island, indicate that where Cercospora infections occur, they are invariably of the mild type.

The hybrids mentioned above have been raised in the course of a breeding programme directed primarily towards the control of Panama disease (Fusarium oxysporum cubense) and their resistance to an entirely different malady is as interesting as it is potentially important. It may also be pointed out that the eight varieties highly resistant to Cercospora are all likewise highly resistant to
Panama disease. The numerous qualities required of a commercial banana remain the same whether it is to be bred resistant to a wilt or to a leaf spot. Evidence has accumulated to show that combining those qualities in a single plant is the real problem of banana breeding, rather than disease resistance alone. The conclusion has already been drawn that the greatest hope of obtaining a good export banana resistant to Panama disease lies in breeding from Gros Michel with appropriate wild species. It follows that the best hope of obtaining a good export banana resistant to Cercospora leaf spot lies in the same directions.

\footnotetext{
1 Wardlaw, Trop. Agric., 11, 7, 173-175 (1934).

Stahel, Trop. Agric., 14, 8, 257-264 (1937).

3 Wardlaw, Trop. Agric., 14, 4, 117-118 (1937).

- Wardlaw, Leonard and Barnell, Trop. Agric., 14, 6 (1939).

- Checsman and Wardlaw, Trop. Aaric., 14, 12, 335-36 (1937).
}

\title{
OBITUARY
}

\section{Dr. E. T. S. Appleyard}

$\mathrm{T}$ HE tragic doath of Dr. E. T. S. Appleyard through injuries caused by a fall came as a great shock to his many friends. He was born in 1904, the son of Edgar Snowden and Elizabeth Appleyard of Huddersfield. He received his school education at Almondbury Grammar School and entered Cambridge as a scholar of King's College. Taking a first class in physics in the Natural Science Tripos, he spent several years on research in the Cavendish Laboratory. In 1929 he was appointed to a George Wills research associateship in the Wills Laboratory at Bristol, a post which he held until his death. During the tenure of this post he was awarded a Rockefeller fellowship for the session 1931-32 in the University of Chicago.

Apployard's first research in the Cavendish Laboratory was on the polarization of the light emitted from atoms bombarded by a directed beam of electrons, and this was afterwards extended to the case of excitation by positive ions.

Following upon a few minor papers in spectroseopy in his carlier years at Bristol, Appleyardembarkedupon a new field to which he made important contributions. With Lovell (Proc. Roy. Soc., 1936, 1937) he investigated the nature of thin metallic films of the alkali metals evaporated on to a cooled surface in vacuo, by measuring their electrical conductivity under varying conditions. This work threw an entirely new light on the subject and cleared up many previous dis. crepancies in the literature. Ho followed this with similar work on mercury films, and with the co-operation of the Royal Society Mond Laboratory and the collaboration of Bristow, Misener and London, he extended the investigation to the superconducting state. A summary of his results on the variation of magnetic field penetration with temperature has already appeared in these columns $(143,433 ; 1939)$, and his last active work was to complete the paper describing the investigation in detail. Its consequences are of much significance and the results have already created considerable interest.

Appleyard was a very able physicist with an acute and critical mind. His wide knowledge, not confined to his own fields of work, made him an invaluable member of a research laboratory. In addition to research he took his share in the teaching and supervision of Part II honours students at Bristol, a number of whom have stated how much they appreciated the thought and time he gave to their interests. Indeed his willingness to be of assistance to everyone in the laboratory, academic and laboratory staff alike, and his desire to ensure that the fullest credit was given to all who helped him in his work, was one of his most lovable characteristics.

Appleyard experienced great pleasure, which his colleagues shared, on the success of his recent experiments on superconductivity, and a fruitful field of research for some years on similar lines seemed to be open to him. It must now be left to others to carry it on. Ho will bo sadly missed.

A. M. TrNDall.

\section{We regret to announce the following deaths :}

Dame Maria Ogilvio Gordon, known for her work on the geology of South Tyrol, on June 24.

Sir Frederick Hobday, C.M.G., honorary veterinary surgeon to the King, formerly principal of the Royal Veterinary College, on June 2t, aged sixty-nine years.

Dr. Witmer Stone, emeritus director of the Academy of Natural Sciences of Philadelphia, on May 23, aged seventy-two years.

Dr. Yojiro Wakiya, formerly director of the Fisheries Institute, Fusan, Chosen, on April 21, aged sixty-seven years. 